\title{
Outcomes of double valve surgery for active infective endocarditis
}

\author{
Amir M. Sheikh, FRCS (C/Th), MBBS, Abdelsalam M. Elhenawy, MD, PhD, Manjula Maganti, MSc, \\ Susan Armstrong, MSc, Tirone E. David, MD, and Christopher M. Feindel, MD
}

Objective: In active infective endocarditis the need for operating simultaneously on the aortic and mitral valves is frequent. There are no studies in the literature documenting long-term outcomes of double valve surgery for active endocarditis.

\begin{abstract}
Methods: Ninety patients underwent double valve surgery for active endocarditis over a 26-year period (mean age, $53 \pm 16$ years; $71 \%$ male patients). Prosthetic endocarditis was seen in 32 patients. Staphylococcus species was isolated in $29 \%$. Forty-six ( $51 \%$ ) patients had abscesses. Surgical intervention consisted of valve repair or replacement with limited infection or radical resection, patch reconstruction, and valve replacement for abscesses. Mean follow-up was $5.9 \pm 4.7$ years (range, $0-18$ years) and was complete.

Results: There were 14 (15.6\%) in-hospital deaths and 29 (32.2\%) late deaths. Overall survival at 5, 7, and 10 years was $68 \% \pm 5 \%, 59 \% \pm 6 \%$, and $49 \% \pm 6 \%$, respectively, and was reduced in those undergoing operations for prosthetic compared with native endocarditis (7-year survival, $39 \% \pm 9 \%$ vs $71 \% \pm 7 \% ; P<.001$ ). Freedom from recurrent endocarditis was $84 \% \pm 5 \%$ at 10 years. Freedom from reoperation was $91 \% \pm 4 \%$ at 10 years. Event-free survival at 7 and 10 years was $60 \% \pm 6 \%$ and $47 \% \pm 7 \%$, respectively. No difference was observed between the native and prosthetic groups for recurrent endocarditis, late reoperation, or event-free survival. Prosthetic endocarditis, increasing age, preoperative shock, and diabetes mellitus were independent predictors of death from all causes.

Conclusions: Double valve surgery for active endocarditis remains technically challenging and associated with significant morbidity and mortality perioperatively and in the longer term. Outcomes are worse in those who have prosthetic valve endocarditis.
\end{abstract}

Extensive tissue destruction and abscess formation in patients with infective endocarditis can make surgical intervention for infective endocarditis especially difficult. Radical debridement and reconstruction form the cornerstone of surgical management in infective endocarditis. ${ }^{1-3}$ The complexity of the operation is markedly increased when more than 1 valve is involved. Double valve surgery (aortic and mitral) for active endocarditis is second in frequency only to isolated aortic valve involvement. ${ }^{4}$ There have been no studies that have documented long-term outcomes of double valve surgery in patients who have active infective endocarditis. We therefore undertook this study.

\section{MATERIALS AND METHODS}

A review of the Toronto General Hospital cardiac surgery database from 1979 to 2004 revealed 90 patients who had undergone surgical intervention for active endocarditis in which both the mitral and aortic valves underwent

\footnotetext{
From the Division of Cardiovascular Surgery, Toronto General Hospital, Toronto, Ontario, Canada.

Received for publication June 30, 2008; revisions received Oct 13, 2008; accepted for publication Nov 22, 2008

Address for reprints: Christopher M. Feindel, MD, Division of Cardiovascular Surgery, Toronto General Hospital, 200 Elizabeth St, 4N-480, Toronto, Ontario, M5G 2C4, Canada (E-mail: Chris.Feindel@uhn.on.ca).

J Thorac Cardiovasc Surg 2009;138:69-75

$0022-5223 / \$ 36.00$

Copyright (C) 2009 by The American Association for Thoracic Surgery

doi:10.1016/j.jtcvs.2008.11.049
}

surgical intervention. Either 1 or both valves had active infection. We included patients undergoing double valve surgery with 1 actively infected valve and a second diseased but noninfected valve because the pathology encountered and the operation required are complex. Patients with remote or healed endocarditis were excluded. Patients with additional endocarditis involvement of the right-sided valves or in whom further surgical intervention was required to the right-sided valves were also excluded. Where necessary, relevant information was also derived by reviewing hospital medical records. Approval was obtained from the ethics review board of the hospital. Indications for surgical intervention were 1 or more of the following: shock, $14(16 \%)$; congestive cardiac failure, $64(72 \%)$; cerebral embolism, 26 (29\%); and perivalvular abscess, $46(51 \%)$. Table 1 shows the clinical characteristics of the patients.

\section{Infecting Organisms}

Data for the infecting organism were available for 75 patients. Staphylococcus species was most commonly encountered: Staphylococcus aureus in $14(16 \%)$ patients and Staphylococcus epidermidis in $12(13 \%)$ patients. Streptococcus viridans was found in $13(14 \%)$ patients, Enterococcus faecalis was found in $8(9 \%)$ patients, other Streptococcus species were found in $13(14 \%)$ patients, Pseudomonas species were found in $2(2 \%)$ patients, other bacteria were found in $4(4 \%)$ patients, and culture-negative endocarditis was found in $9(10 \%)$ patients.

\section{Operative Procedures}

The extent of tissue destruction from the endocarditis was assessed. Where infection was limited to the leaflets of the native or prosthetic valve, simple replacement or repair, if feasible, in the case of the mitral valve, was performed. Where infection had extended to or beyond the annulus, surgical intervention consisted of radical resection of all infected tissue, followed by reconstruction as necessary with valve replacement, as has been previously 


\section{Abbreviations and Acronyms \\ $\mathrm{CI}=$ confidence interval \\ $\mathrm{HR}=$ hazard ratio}

described..$^{1-3,5}$ Pre-existing mitral and aortic valve pathology is described in Table 2. Operative data are summarized in Table 3. The average cardiopulmonary bypass time was $158 \pm 60$ minutes with a crossclamp time of $124 \pm 42$ minutes.

\section{Follow-up}

All patients were reviewed annually by the referring cardiologist, and data were collected prospectively. Our dedicated research personnel verified all cardiac events and maintained a comprehensive database. The mean follow-up was $5.9 \pm 4.7$ years (range, $0-18$ years) and was complete.

\section{Statistics}

Continuous variables were reported as the mean \pm standard deviation. All data analyses were performed with SAS 9.1 Software (SAS Institute, Inc, Cary, NC). Fisher's exact or $\chi^{2}$ tests were used to evaluate categorical variables univariately and were reported as frequencies. Student's $t$ test was used to analyze continuous variables that had normal distribution, and the Wilcoxon rank test was used for variables that had nonparametric distribution. The Kaplan-Meier method was used to calculate estimates for longterm survival, freedom from late reoperation, freedom from recurrent endocarditis, and event-free survival. Event-free survival was defined as the freedom from thromboembolism (including stroke), valve thrombosis, hemolysis, structural valve dysfunction, perivalvular leak, major bleeding event, endocarditis, reoperation, and death in hospital survivors. In line with the recent Society of Thoracic Surgeons guidelines on reporting outcomes after valve surgery, ${ }^{6}$ we have defined operative mortality as death within 90 days of the operation. All preoperative variables with a univariate $P$ value of less than .25 or those judged to be clinically important were submitted to the multivariable model for Cox regression analysis to determine the independent predictors of operative and late deaths.

\section{RESULTS}

Eighty-one patients had active endocarditis involving both the aortic and mitral valves. In 9 patients there was active infection of one valve, and the other valve also underwent surgical intervention for the following reasons: dilated mitral annulus, 2; myxomatous or prolapsing mitral valve, 2 ; rheumatic mitral valve, 1 ; ischemic mitral valve, 1 ; rheumatic aortic valve, 1 ; and prolapsing aortic valve, 2 .

There were $14(16 \%)$ operative deaths (death within 90 days). Operative mortalities are summarized for the various subgroups in Table 4. Although cause of death was usually multifactorial, the main causes were as follows: cardiogenic shock, 5; cardiac arrest, 1; stroke, 3; multiorgan failure, 3; excessive postoperative hemorrhage, 1 ; and failure to wean from cardiopulmonary bypass, 1 . In this group, of the significant factors identified in the univariate analysis for operative deaths, prosthetic endocarditis was present in 9 patients, diabetes in 5 patients, hypertension in 6 patients, and preoperative shock in 7 patients. Of borderline statistical significance was female sex $(P=.058) ; 7$ patients were female. Ten patients had paravalvular abscesses. Double
TABLE 1. Clinical characteristics

\begin{tabular}{|c|c|c|}
\hline & No. & Percentage \\
\hline Mean age (y) & $53.3 \pm 15.8$ & \\
\hline Male sex & 64 & 71 \\
\hline \multicolumn{3}{|l|}{ Comorbid conditions } \\
\hline Diabetes mellitus & 13 & 15 \\
\hline Hypertension & 19 & 22 \\
\hline Chronic obstructive lung disease & 7 & 8 \\
\hline Renal failure & 20 & 22 \\
\hline Recent myocardial infarction $(<30 \mathrm{~d})$ & 2 & 2 \\
\hline $\begin{array}{l}\text { Recent stroke or transient ischemic } \\
\text { attack }(<30 \mathrm{~d})\end{array}$ & 26 & 29 \\
\hline Peripheral vascular disease & 4 & 5 \\
\hline \multicolumn{3}{|l|}{ New York Heart Association class } \\
\hline I & 3 & 3 \\
\hline II & 4 & 5 \\
\hline III & 6 & 7 \\
\hline IV & 76 & 85 \\
\hline \multicolumn{3}{|l|}{ Preoperative rhythm } \\
\hline Sinus rhythm & 69 & 77 \\
\hline Atrial fibrillation & 21 & 23 \\
\hline Cardiogenic or septic shock & 14 & 16 \\
\hline Congestive cardiac failure & 64 & 72 \\
\hline \multicolumn{3}{|l|}{ Endocarditis } \\
\hline Native & 58 & 64 \\
\hline Prosthetic & 32 & 36 \\
\hline Previous cardiac surgery & 34 & 38 \\
\hline Coronary artery bypass & 5 & 6 \\
\hline Aortic valve replacement & 27 & 30 \\
\hline Aortic valve repair & 1 & 1 \\
\hline Mitral valve repair & 1 & 1 \\
\hline Mitral valve replacement & 18 & 20 \\
\hline Tricuspid valve repair & 0 & \\
\hline Aortic annular enlargement & 27 & 35 \\
\hline Annulus & 12 & 15 \\
\hline Sinuses & 4 & 5 \\
\hline Both & 11 & 14 \\
\hline \multicolumn{3}{|l|}{ Left ventricular ejection fraction } \\
\hline$\geq 40 \%$ & 71 & 85 \\
\hline$<40 \%$ & 13 & 16 \\
\hline \multicolumn{3}{|l|}{ Timing of operation } \\
\hline Elective/same hospitalization & 35 & 42 \\
\hline Urgent/emergency & 49 & 58 \\
\hline
\end{tabular}

TABLE 2. Pre-existing valve pathology

\begin{tabular}{lrc}
\hline & No. & Percentage \\
\hline Aortic valve pathology & & \\
Bicuspid & 15 & 17 \\
Rheumatic & 8 & 9 \\
Calcific degeneration & 7 & 8 \\
Prosthetic dysfunction & 16 & 18 \\
Mitral valve pathology & & \\
Rheumatic & 12 & 13 \\
Myxomatous & 5 & 6 \\
Ischemic & 1 & 1 \\
Prosthetic dysfunction & 11 & 12 \\
Annular dilatation & 2 & 2 \\
\hline
\end{tabular}


TABLE 3. Operative data

\begin{tabular}{|c|c|c|}
\hline & No. & Percentage \\
\hline \multicolumn{3}{|l|}{ Mitral valve operation performed } \\
\hline Mitral valve repair & 25 & 28 \\
\hline Mitral valve replacement & 65 & 72 \\
\hline \multicolumn{3}{|l|}{ Mitral valve prosthesis used } \\
\hline Mechanical & 46 & 51 \\
\hline Bioprosthesis & 19 & 21 \\
\hline Repair ring/band & 7 & 8 \\
\hline Mitral valve annulus reconstruction & 29 & 29 \\
\hline Autologous pericardium & 8 & 9 \\
\hline Bovine pericardium & 18 & 20 \\
\hline \multicolumn{3}{|l|}{ Chordal preservation in mitral valve replacement } \\
\hline Posterior only & 10 & 11 \\
\hline Anterior and posterior & 10 & 11 \\
\hline Polytetrafluoroethylene* sutures & 14 & 16 \\
\hline \multicolumn{3}{|l|}{ Aortic valve operation performed } \\
\hline Aortic valve replacement & 78 & 87 \\
\hline Tissue prosthesis & 27 & 30 \\
\hline Mechanical prosthesis & 51 & 57 \\
\hline Aortic root replacement & 12 & 13 \\
\hline Composite mechanical graft & 5 & 6 \\
\hline Freestyle stentless & 2 & 2 \\
\hline Composite tailored tissue graft & 1 & 1 \\
\hline Homograft & 4 & 4 \\
\hline Reconstruction of intervalvular fibrous body & 25 & 28 \\
\hline \multicolumn{3}{|l|}{ Concomitant procedures } \\
\hline Coronary artery bypass grafting & 12 & 13 \\
\hline Replacement of supracoronary ascending aorta & 2 & 2 \\
\hline Abscess & 46 & 51.1 \\
\hline
\end{tabular}

*Gore-Tex sutures; W. L. Gore \& Associates, Inc, Newark, Del.

valve replacement with reconstruction of the intervalvular fibrous body and aortic root replacement were not associated with increased operative mortality. When examining for any change over time, we found no difference in operative mortality between the first and second halves of the study ( $17 \%$ for 1979-1994 vs 14\% for 1995-2004, $P=.69$ ).

The mean stay in the intensive care unit was $7.9 \pm 18.3$ days (median, 3 days), with mean ventilation times of 4.4 \pm 12 days (median, 1 day). Postoperative complications are summarized in Table 5. Mean hospital stay was $19 \pm$ 15 days (median, 16 days). Six patients required repeat operations during the same admission, 5 for technical complications: mitral annulus patch dehiscence, 2; Gerbode-type ventricular septal defect, 1; ascending aortic false aneurysm, 1 ; aortic sinus fistula to the pulmonary artery, 1 ; and recurrent endocarditis, 1 . There was 1 death associated with these repeat early operations. There were no cases of deep sternal wound infection.

A further 29 patients died during follow-up. There were 10 valve-related deaths (recurrent endocarditis in 6, perivalvular leak in 1, anticoagulation-related hemorrhage in 1, cardiac arrest in 1 , and sudden death in 1) and a further 10 cardiac deaths (congestive heart failure in 6 and myocardial infarction in 4). There were 9 noncardiac deaths (cancer in 6, renal
TABLE 4. Operative mortalities in various subgroups

\begin{tabular}{|c|c|c|c|}
\hline Variable & No. & Mortality (\%) & $P$ value \\
\hline \multicolumn{4}{|l|}{ Patient characteristics } \\
\hline Native endocarditis & 58 & 8.6 & \\
\hline Prosthetic endocarditis & 32 & 28.1 & .015 \\
\hline Female sex & 26 & 26.9 & .058 \\
\hline Diabetes & 13 & 38.5 & .015 \\
\hline Hypertension & 19 & 31.6 & .02 \\
\hline Preoperative shock & 14 & 50 & .0001 \\
\hline Preoperative renal failure & 20 & 20 & .5 \\
\hline $\begin{array}{l}\text { Preoperative stroke, } \\
\text { transient ischemic attack }\end{array}$ & 26 & 23.1 & .22 \\
\hline Preoperative atrial fibrillation & 21 & 4.8 & .17 \\
\hline $\begin{array}{l}\text { Preoperative congestive } \\
\text { heart failure }\end{array}$ & 64 & 17.2 & .75 \\
\hline Preoperative syncope & 5 & 40 & .178 \\
\hline Paravalvular abscess & 46 & 21.7 & .15 \\
\hline Staphylococcus aureus & 14 & 14.3 & 1 \\
\hline Ejection fraction $<40 \%$ & 13 & 15.4 & 1 \\
\hline \multicolumn{4}{|l|}{ NYHA class } \\
\hline $\mathrm{I} / \mathrm{II} / \mathrm{III}$ & 13 & 7.69 & \\
\hline IV & 76 & 17.1 & .68 \\
\hline \multicolumn{4}{|l|}{ Timing of operation } \\
\hline Elective/same hospitalization & 35 & 8.6 & \\
\hline Urgent/emergency & 49 & 18.4 & .34 \\
\hline Any redo operation & 34 & 26.5 & .026 \\
\hline Previous mitral valve surgery & 19 & 31.6 & .03 \\
\hline Previous aortic valve surgery & 28 & 25 & .097 \\
\hline \multicolumn{4}{|l|}{ Operative factors } \\
\hline Mitral valve chordal preservation & 20 & 15 & 1 \\
\hline Mitral valve annulus reconstruction & 26 & 23.1 & .24 \\
\hline Mitral valve repair & 25 & 4 & .1 \\
\hline Mitral valve replacement & 65 & 20 & \\
\hline \multicolumn{4}{|l|}{ Aortic valve prosthesis } \\
\hline Tissue & 34 & 14.7 & \\
\hline Mechanical & 56 & 16.1 & .86 \\
\hline $\begin{array}{l}\text { Double valve replacement with } \\
\text { reconstruction of intervalvular } \\
\text { fibrous body }\end{array}$ & 25 & 20 & .47 \\
\hline Aortic root replacement & 12 & 8.3 & 1 \\
\hline
\end{tabular}

failure in 2, and bowel ischemia in 1). Survival was $68 \% \pm$ $5 \%, 59 \% \pm 6 \%$, and $49 \% \pm 6 \%$ at 5,7 , and 10 years, respectively (Figure 1). Survival was greater in those undergoing operations for native valve endocarditis than for prosthetic valve endocarditis (7-year survival, $71 \% \pm 6 \%$ vs $39 \% \pm 9 \%$, respectively; $P<.001$; Figure 2 ). Cox regression analysis identified diabetes (hazard ratio [HR], 4.91; 95\% confidence interval $[\mathrm{CI}], 2.15-11.23 ; P<.001)$, prosthetic valve endocarditis (HR, 4.1; 95\% CI, 1.92-8.56; $P<.001$ ), preoperative shock (HR, 2.63; 95\% CI, 1.1-6.3; $P=.03$ ), and increased age (HR, 1.3; 95\% CI, 1.14-1.54; $P<.001)$ as independent predictors of death from all causes. Double valve replacement with reconstruction of the intervalvular fibrous body, a sizeable surgical undertaking, and aortic root replacement were not predictors of late death. 
TABLE 5. Postoperative complications

\begin{tabular}{|c|c|c|c|}
\hline Complication & No. & $\begin{array}{c}\text { Associated } \\
\text { mortality (\%) }\end{array}$ & $P$ value \\
\hline \multicolumn{4}{|l|}{ Reopening } \\
\hline For bleeding & 8 & 25 & .61 \\
\hline For tamponade & 3 & 0 & \\
\hline Arrest & 1 & 100 & \\
\hline Redo operation & 6 & 17 & 1 \\
\hline Stroke & 5 & 80 & .002 \\
\hline Intraoperative & 3 & & \\
\hline Postoperative & 2 & & \\
\hline Renal failure & 7 & 57.1 & .012 \\
\hline Sepsis & 4 & 0 & 1 \\
\hline Pulmonary complications & 22 & 9.1 & .5 \\
\hline $\begin{array}{l}\text { Insertion of permanent } \\
\text { pacemaker }\end{array}$ & 12 & 16.7 & 1 \\
\hline Need for inotropes & 68 & 17.7 & .5 \\
\hline
\end{tabular}

Recurrence of endocarditis was seen in 10 patients. Of the significant factors associated with operative and late deaths, prosthetic endocarditis was present in 2 patients, and preoperative shock was present in 2 patients. Paravalvular abscess was present in 6 patients at the first operation for endocarditis. Four had early endocarditis ( $\leq 1$ year). The infecting organism was different from the original episode in 5 patients and the same in 1 patient, and in 4 patients this information was missing because the patients were readmitted to other hospitals. Three of these patients underwent reoperations and survived. Of the 7 patients managed conservatively with antibiotic therapy, there was only 1 survivor. Of the 6 endocarditis-related deaths, 1 was an intravenous drug abuser. Freedom from recurrent endocarditis overall was $88 \% \pm 4 \%$ at 5 years and $84 \% \pm 5 \%$ at 10 years. There was no significant difference in freedom from recurrence of endocarditis between the native and prosthetic endocarditis groups (7-year freedom from endocarditis was $80 \% \pm 6 \%$ for native valve and $95 \% \pm 5 \%$ for prosthetic endocarditis, $P=.16$ ).

Late morbidity events are summarized in Table 6 . There were no instances of valve hemolysis. There were 10 late re-

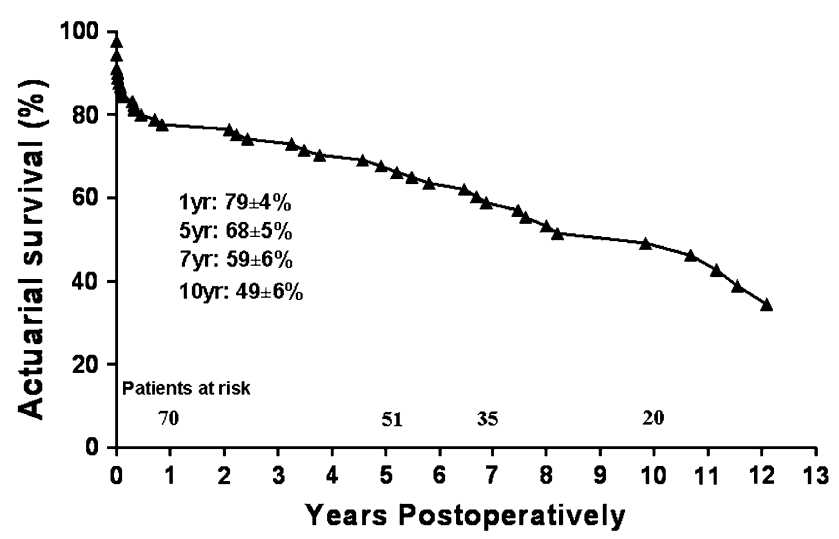

FIGURE 1. Long-term actuarial survival for all patients.

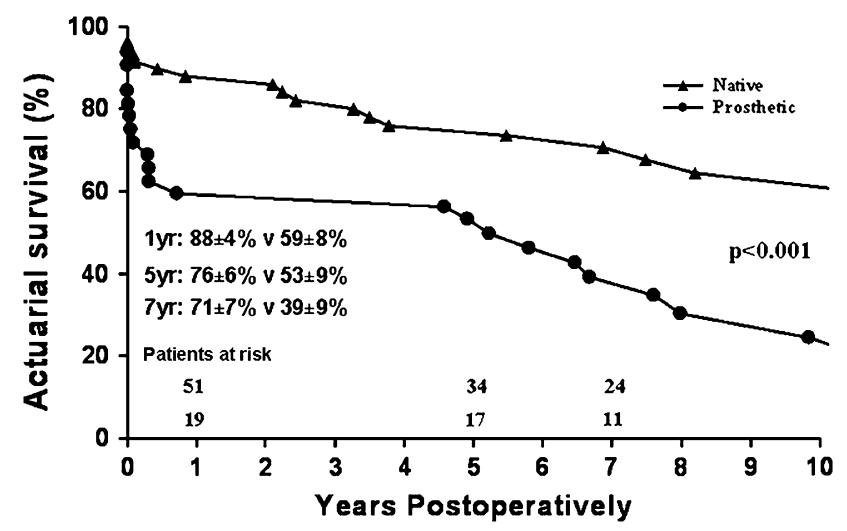

FIGURE 2. Long-term actuarial survival for the native versus prosthetic endocarditis groups.

operations, for which there were no operative mortalities for patients undergoing reoperation. In one of the 3 patients requiring a reoperation for paravalvular leak, mitral annulus patch reconstruction with bovine pericardium had been performed, and the patch had subsequently calcified and fractured, giving rise to mitral prosthesis dehiscence. Freedom from reoperation was $93 \% \pm 4 \%$ at 7 years and $90 \% \pm$ $4 \%$ at 10 years (Figure 3 ). Freedom from reoperation was similar between the native and prosthetic endocarditis groups (at 7 years, $92 \% \pm 5 \%$ vs $95 \% \pm 5 \% ; P=.72$ ).

At the latest follow-up, 47 patients were alive, of whom 38 were free from reoperation and were in New York Heart Association functional class I (27 [71\%]), II (7 [18\%]), and III (4 [11\%]). Overall event-free survival at 7 and 10 years was $60 \% \pm 6 \%$ and $47 \% \pm 7 \%$, respectively, and no difference was observed between the native and prosthetic groups (at 7 years, $65 \% \pm 7 \%$ vs $51 \% \pm 11 \% ; P=.21$; Figure 4). In analyzing the patient and operative characteristics of the prosthetic and native endocarditis groups, the groups were similar other than a higher incidence of preoperative atrial fibrillation $(43 \%$ vs $12 \%, P<.001)$ but a lower incidence of congestive heart failure $(50 \%$ vs $84 \%, P<$ $.001)$ and New York Heart Association class IV (72\% vs $93 \%, P=.01)$ in the patients with prosthetic endocarditis, respectively. The incidence of abscess was similar in both groups (prosthetic, $63 \%$ vs $45 \% ; P=.1$ ).

We also examined long-term outcomes in patients who had at least 1 abscess at the time of surgical intervention with those who had no abscess formation. Paravalvular abscess was associated with an operative mortality of $21.7 \%$ versus $9.1 \%$ $(P=.15)$, and no difference was seen between groups in actuarial survival or for freedom from recurrent endocarditis, freedom from reoperation, or event-free survival.

Four patients in our series underwent aortic homograft root replacement. Three of these had concurrent mitral valve repair and are alive and free from reoperation and recurrent endocarditis at the latest follow-up (longest of 10 years). One patient 
TABLE 6. Late morbidity events

\begin{tabular}{lcc}
\hline \multicolumn{1}{c}{ Complication } & No. & Died \\
\hline Endocarditis recurrence & 10 & 6 \\
Thromboembolic events & & 0 \\
$\quad$ Stroke & 2 & \\
Transient ischemic attack & 3 & \\
Reoperations & 10 & \\
Bioprosthetic structural valve deterioration & 1 & \\
Recurrent endocarditis & 3 & \\
Perivalvular leak & 3 & \\
Pannus formation & 1 & \\
$\quad$ Recurrent mitral regurgitation & 2 & 1 \\
Perivalvular leak & 5 & \\
Major anticoagulation-related hemorrhage & 3 & \\
Valve thrombosis & 1 & \\
\hline
\end{tabular}

had concurrent mitral valve replacement and died postoperatively from stroke. No patients had mitral homografts.

\section{DISCUSSION}

There have been a number of studies that have examined surgical outcomes after infective endocarditis. ${ }^{4,7,8}$ We have previously found that surgical intervention for active endocarditis most commonly comprised isolated aortic valve surgery, followed in equal frequency by isolated mitral valve surgery and double valve (aortic and mitral) surgery. ${ }^{4}$ There have, to date, been no reports on the long-term outcomes of patients with active endocarditis in whom both the aortic and mitral valves underwent surgical intervention.

We have presented the early and late outcomes of double valve surgery for active infective endocarditis in a cohort of 90 patients over a 26 -year period. A significant mortality $(15.6 \%)$ was seen in the short term and also in the longer term, with a $51 \%$ mortality at 10 years. Postoperative recovery was protracted: in our series the mean intensive care unit stay was 8 days, with a mean hospital stay of 19 days, and complications were common. One third of late deaths were valve related, and the incidence of recurrent endocarditis was $13 \%$ in hospital survivors.

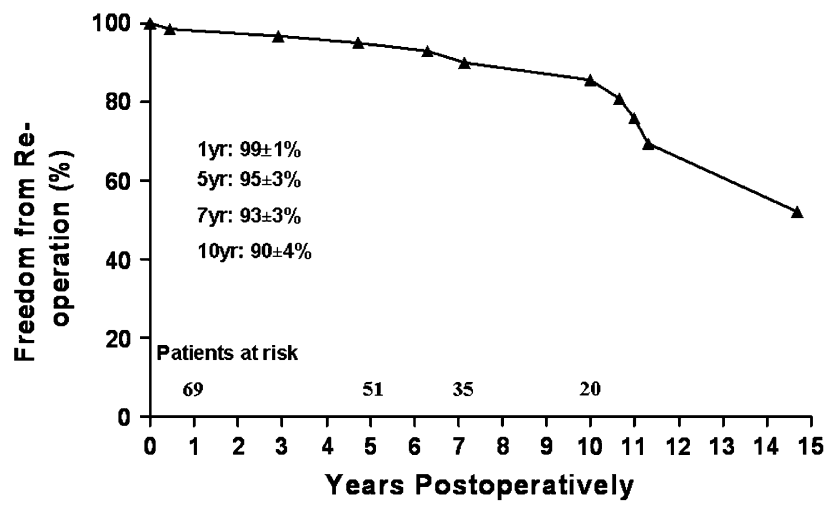

FIGURE 3. Long-term freedom from reoperation for all patients.

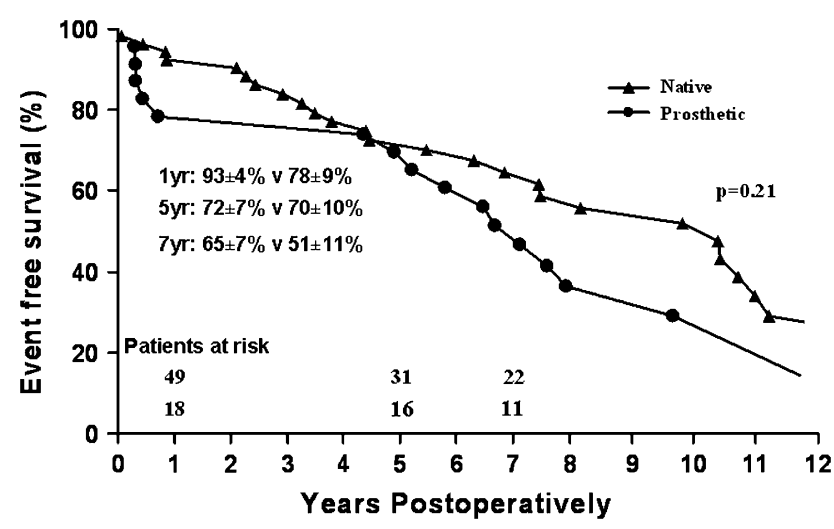

FIGURE 4. Event-free survival for the native versus prosthetic groups.

Gillinov and colleagues ${ }^{7}$ from the Cleveland Clinic reported on the surgical outcomes of 54 patients with native double valve endocarditis over a 22 -year period. There were no operative mortalities and 9 late deaths, with a 10 -year actuarial survival of $73 \%$. In their series, however, the endocarditis was active in only half and remote/healed in the other half. Patients with active endocarditis tend to be sicker than those undergoing surgical intervention for healed endocarditis, and greater tissue destruction is likely to be encountered. This makes surgical risk greater in patients with active endocarditis. The degree of tissue destruction appears to be more limited in comparison with that seen in our series. Only $11 \%$ had abscesses, and there was no contiguous spread between valves or involvement of the fibrous trigones. By contrast, $51 \%$ of our patients had abscesses, and intervalvular fibrous body involvement necessitating patch reconstruction, a tremendous surgical undertaking, was required in $28 \%$. Gillinov and colleagues ${ }^{7}$ determined increasing age and earlier date of operation to be independent predictors of late death by means of multivariate analysis. We also identified increasing age as a predictor of late death.

The Cleveland Clinic series was confined to native valve infection. It is well established that prosthetic valve endocarditis carries a worse outcome than native valve endocarditis. ${ }^{4,9,10}$ In our study prosthetic endocarditis was associated with increased operative mortality and was also a significant independent predictor of late death. Interestingly, there was no difference between the groups in freedom from recurrent endocarditis, freedom from reoperation, and event-free survival, with the latter being a measure of overall morbidity and mortality in hospital survivors. It appears that the greater long-term mortality for prosthetic endocarditis relates to the higher operative mortality and that survivors' late morbidity and mortality become similar to that for native endocarditis, as is evident from Figure 2. This effect appears independent of the incidence of abscesses because there was no significant difference between the native and prosthetic groups for abscess formation. 
Siniawski and associates ${ }^{11}$ evaluated hospital mortality in 108 surgical patients with active endocarditis and the presence of an aortic root abscess. Hospital mortality was $17.6 \%$, and they identified, using multivariable analysis, the need for double valve surgery as strongly predicative of death, along with female sex, shock, and left ventricular dysfunction or dilatation. They further evaluated 53 patients who underwent operations for aortic valve endocarditis with secondary infection of the mitral valve. Hospital mortality was $26 \%$ overall and highest $(29 \%)$ in the group requiring aortic root replacement with mitral valve repair/replacement. Independent predictors of death were contiguous spread of infection from the aortic to the mitral valve, whereas jet lesion involvement of the mitral valve was not a risk factor.

Surgical management of a paravalvular abscess can be technically challenging. After radical debridement of an abscess, complex reconstructive surgery might be required. We have previously found paravalvular abscess to be an independent predictor of operative mortality in all patients undergoing surgical intervention for active infective endocarditis. ${ }^{4}$ Surgical intervention for endocarditis (of any valve) complicated by a paravalvular abscess was associated with high operative mortality $(15.5 \%)$ and a 10 -year actuarial survival of $57 \% .^{12}$ In our current study almost half the patients undergoing double valve surgery for active endocarditis had at least 1 abscess, and frequently multiple abscesses were present. In keeping with our previous work, a paravalvular abscess was again found to be associated with high operative mortality $(21.7 \%)$, although this did not reach statistical significance $(P=.15)$.

It is not surprising that highly complex operations might be necessary in patients with active endocarditis in whom both the aortic and mitral valves require intervention. Aortic root replacement was performed in 12 patients, 4 with a homograft. Ten of these patients had aortic root abscesses, sometimes enveloping the coronary arteries, which required modified Cabrol interposition grafts to reattach the coronary arteries. Double valve replacement with reconstruction of the intervalvular fibrous body was performed in 25 patients, 19 of whom had abscess formation. Remarkably, such complex procedures were not associated with increased operative mortality nor were they predictors of long-term death. It is noteworthy that in this series early redo operations (ie, within the same hospital admission) were required in 6 $(6.7 \%)$ patients. This is indicative of the extent of tissue destruction that was seen and the complexity of reconstruction that was required. Although there is much discussion regarding the use of homografts in active endocarditis, ${ }^{13,14}$ we would emphasize that homograft use does not substitute for the principle of radical debridement with appropriate reconstruction. Mitral homograft use is rare, ${ }^{15}$ and no benefit is obtained by performing aortic homograft replacement if a stented mitral prosthesis is used.
In addition to increasing age and prosthetic endocarditis, preoperative shock and diabetes mellitus were independent predictors of death from all causes. Preoperative shock is well documented as being an independent risk factor for operative and late death. ${ }^{411,12,16}$ Diabetes mellitus is increasingly being identified as a risk factor for in-hospital mortality in patients with infective endocarditis who are medically treated, ${ }^{17-19}$ as well as those undergoing surgical intervention. ${ }^{16,20}$ A French prospective population-based survey found insulin-dependent diabetes mellitus to be an independent predictor of in-hospital death (odds ratio, 7.82 ) in 559 cases of definite infective endocarditis. ${ }^{18}$ Subanalysis demonstrated insulin-dependent diabetes to be associated with greater mortality $(50 \%$ vs $19 \%)$ than oral medication-treated diabetes and remained predictive of death, whereas the latter was not predictive of death. ${ }^{19}$

Rosamel and coworkers ${ }^{20}$ noted diabetes mellitus to be associated with increased operative mortality in 98 patients undergoing surgical intervention for active endocarditis of any valve. Of 6627 patients in a large retrospective review of the Society of Thoracic Surgeons National Cardiac Database, Gammie and colleagues ${ }^{16}$ found diabetes to be an independent predictor of operative mortality when examining outcomes of surgical intervention for mitral valve endocarditis (odds ratio, 1.59), although only $40 \%$ of the cohort had active endocarditis. To the best of our knowledge, this is the first report that demonstrates diabetes to be an independent predictor of long-term death after surgical intervention for endocarditis.

In summary, we have presented the early and late outcomes of double valve surgery for active infective endocarditis. Double valve surgery is a substantial undertaking in the setting of active endocarditis. Operative mortality and perioperative morbidity are significant, but reasonable long-term survival can be achieved. Good freedom from reoperation and recurrent endocarditis are seen. Survival is worse in patients with prosthetic valve endocarditis, but hospital survivors attain event-free survival comparable with that of patients with native valve endocarditis.

\section{References}

1. d'Udekem Y, David TE, Feindel CM, Armstrong S, Sun Z. Long-term results of surgery for active infective endocarditis. Eur J Cardiothorac Surg. 1997;11:46-52.

2. David TE, Komeda M, Brofman PR. Surgical treatment of aortic root abscess. Circulation. 1989;80:I269-74.

3. David TE, Feindel CM, Armstrong S, Sun Z. Reconstruction of the mitral anulus. A ten-year experience. J Thorac Cardiovasc Surg. 1995;110:1323-32.

4. David TE, Gavra G, Feindel CM, Regesta T, Armstrong S, Maganti MD. Surgical treatment of active infective endocarditis: a continued challenge. $J$ Thorac Cardiovasc Surg. 2007;133:144-9.

5. David TE, Kuo J, Armstrong S. Aortic and mitral valve replacement with reconstruction of the intervalvular fibrous body. J Thorac Cardiovasc Surg. 1997;114: 766-71.

6. Akins CW, Miller DC, Turina MI, Kouchoukos NT, Blackstone EH, Grunkemeier GL, et al. Guidelines for reporting mortality and morbidity after cardiac valve interventions. Ann Thorac Surg. 2008;85:1490-5.

7. Gillinov AM, Diaz R, Blackstone EH, Pettersson GB, Sabik JF, Lytle BW, et al. Double valve endocarditis. Ann Thorac Surg. 2001;71:1874-9. 
8. Kaiser SP, Melby SJ, Zierer A, Schuessler RB, Moon MR, Moazami N, et al. Long-term outcomes in valve replacement surgery for infective endocarditis. Ann Thorac Surg. 2007;83:30-5.

9. Wang A, Pappas P, Anstrom KJ, Abrutyn E, Fowler VG Jr, Hoen B, et al. The use and effect of surgical therapy for prosthetic valve infective endocarditis: a propensity analysis of a multicenter, international cohort. Am Heart J. 2005;150: 1086-91.

10. Wang A, Athan E, Pappas PA, Fowler VG Jr, Olaison L, Pare C, et al. Contemporary clinical profile and outcome of prosthetic valve endocarditis. JAMA. 2007; 297:1354-61.

11. Siniawski H, Grauhan O, Hofmann M, Pasic M, Weng Y, Yankah C, et al. Aortic root abscess and secondary infective mitral valve disease: results of surgical endocarditis treatment. Eur J Cardiothorac Surg. 2005;27:434-40.

12. David TE, Regesta T, Gavra G, Armstrong S, Maganti MD. Surgical treatment of paravalvular abscess: long-term results. Eur $J$ Cardiothorac Surg. 2007;31:43-8.

13. Hagl C, Galla JD, Lansman SL, Fink D, Bodian CA, Spielvogel D, et al. Replacing the ascending aorta and aortic valve for acute prosthetic valve endocarditis: is using prosthetic material contraindicated? Ann Thorac Surg. 2002;74(suppl): S1781-5.
14. Sabik JF, Lytle BW, Blackstone EH, Marullo AG, Pettersson GB, Cosgrove DM. Aortic root replacement with cryopreserved allograft for prosthetic valve endocarditis. Ann Thorac Surg. 2002;74:650-9.

15. Obadia JF, Henaine R, Bergerot C, Ginon I, Nataf P, Chavanis N, et al. Monobloc aorto-mitral homograft or mechanical valve replacement: a new surgical option for extensive bivalvular endocarditis. J Thorac Cardiovasc Surg. 2006;131:243-5.

16. Gammie JS, O'Brien SM, Griffith BP, Peterson ED. Surgical treatment of mitral valve endocarditis in North America. Ann Thorac Surg. 2005;80:2199-204.

17. Chu VH, Cabell CH, Benjamin DK Jr, Kuniholm EF, Fowler VG Jr, Engemann J et al. Early predictors of in-hospital death in infective endocarditis. Circulation. 2004; 109:1745-9.

18. Delahaye F, Alla F, Beguinot I, Bruneval P, Doco-Lecompte T, Lacassin F, et al In-hospital mortality of infective endocarditis: prognostic factors and evolution over an 8-year period. Scand J Infect Dis. 2007;39:849-57.

19. Duval X, Alla F, Doco-Lecompte T, Le Moing V, Delahaye F, Mainardi JL, et al Diabetes mellitus and infective endocarditis: the insulin factor in patient morbidity and mortality. Eur Heart J. 2007;28:59-64.

20. Rosamel P, Cervantes M, Tristan A, Thivolet-Bejui F, Bastien O, Obadia JF, et al. Active infectious endocarditis: postoperative outcome. I Cardiothorac Vasc Anesth. 2005;19:435-9. 